\title{
BMJ Open Assessment of equity in healthcare financing in Fiji and Timor-Leste: a study protocol
}

Augustine D Asante, ${ }^{1}$ Jennifer Price, ${ }^{1}$ Andrew Hayen, ${ }^{1}$ Wayne Irava, ${ }^{2}$ Joao Martins, ${ }^{3}$ Lorna Guinness, ${ }^{4}$ John E Ataguba, ${ }^{5}$ Supon Limwattananon, ${ }^{6}$ Anne Mills, ${ }^{7}$ Stephen Jan, ${ }^{8}$ Virginia Wiseman ${ }^{1,9}$

To cite: Asante AD, Price J, Hayen A, et al. Assessment of equity in healthcare financing in Fiji and Timor-Leste: a study protocol. BMJ Open 2014;4:e006806.

doi:10.1136/bmjopen-2014006806

- Prepublication history for this paper is available online. To view these files please visit the journal online (http://dx.doi.org/10.1136/ bmjopen-2014-006806).

Received 2 October 2014 Accepted 27 October 2014

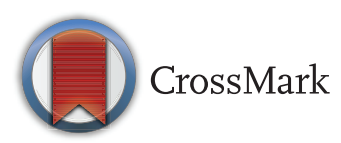

For numbered affiliations see end of article.

Correspondence to Dr Augustine D Asante; a.asante@unsw.edu.au

\section{ABSTRACT}

Introduction: Equitable health financing remains a key health policy objective worldwide. In low and middleincome countries (LMICs), there is evidence that many people are unable to access the health services they need due to financial and other barriers. There are growing calls for fairer health financing systems that will protect people from catastrophic and impoverishing health payments in times of illness. This study aims to assess equity in healthcare financing in Fiji and Timor-Leste in order to support government efforts to improve access to healthcare and move towards universal health coverage in the two countries.

Methods and analysis: The study employs two standard measures of equity in health financing increasingly being applied in LMICs—benefit incidence analysis (BIA) and financing incidence analysis (FIA). In Fiji, we will use a combination of secondary and primary data including a Household Income and Expenditure Survey, National Health Accounts, and data from a crosssectional household survey on healthcare utilisation. In Timor-Leste, the World Bank recently completed a health equity and financial protection analysis that incorporates BIA and FIA, and found that the distribution of benefits from healthcare financing is pro-rich. Building on this work, we will explore the factors that influence the prorich distribution.

Ethics and dissemination: The study is approved by the Human Research Ethics Committee of University of New South Wales, Australia (Approval number: HC13269); the Fiji National Health Research Committee (Approval \# 201371); and the Timor-Leste Ministry of Health (Ref MS/UNSW/NI/218).

Results: Study outcomes will be disseminated through stakeholder meetings, targeted multidisciplinary seminars, peer-reviewed journal publications, policy briefs and the use of other web-based technologies including social media. A user-friendly toolkit on how to analyse healthcare financing equity will be developed for use by policymakers and development partners in the region.

\section{INTRODUCTION}

Equity in health financing remains a key health policy objective worldwide. Evidence from low and middle-income countries (LMICs) suggests that many people, often from low socioeconomic backgrounds, are unable to access the health services they need due to financial and other barriers. ${ }^{12}$ The World Health Report 2000 stipulates that a key dimension of a health system's performance is the fairness of its financing system. ${ }^{3}$ The more recent World Health Report 2010 on universal health coverage (UHC) reinforces the need for fairer healthcare financing. ${ }^{4}$ Globally, it is estimated that about 150 million people suffer financial catastrophe every year due to out-of-pocket (OOP) payments for health services they need and over 100 million are pushed below the poverty line. ${ }^{5}$

The thrust of universal coverage is that all people should have access to the health services they need without risking financial ruin or impoverishment. ${ }^{56}$ Achieving this requires a well-functioning health financing system that ensures the burden of healthcare payment is distributed according to ability-to-pay (ATP) and the benefits from healthcare spending are distributed in accordance with the need for these services. ${ }^{7}$ Traditionally, health systems are financed through four main sources: taxation, social health insurance contributions, private health insurance premiums and OOP payments. $^{8}$ The degree of equity of a health financing system depends crucially on how these different financing sources interact (figure 1 shows the interaction among different sources of healthcare financing and services delivery). It is generally accepted that a government tax financed healthcare benefits the poor more than the rich. ${ }^{10}$

A pro-poor publicly financed healthcare system is particularly important given the growing pluralism of healthcare systems in LMICs. Households in LMICs use a wide range of public and private healthcare providers, many of whom are not regulated by 
Figure 1 Interactions among different sources of healthcare financing and service delivery. Source: Schieber et al. ${ }^{9}$

\begin{tabular}{|c|c|c|c|}
\hline $\begin{array}{l}\text { Revenue } \\
\text { collection }\end{array}$ & Pooling & $\begin{array}{l}\text { Resource allocation } \\
\text { and purchasing (RAP) }\end{array}$ & $\begin{array}{c}\text { Service } \\
\text { provision }\end{array}$ \\
\hline
\end{tabular}



national health authorities ${ }^{11}$ and may be paid for directly OOP $^{12}$ On average, almost $50 \%$ of healthcare financing in low-income countries and $30 \%$ in middle-income countries come from OOP payments. ${ }^{13}$ While little is known about OOP expenditure in the Pacific, increasing evidence is available for Asia. For example, in Pakistan, Laos, The Philippines, Bangladesh and Vietnam, OOP payments represent more than $50 \%$ of total health expenditure. ${ }^{14}$ In India, the cost of treatment for illness is reported to cause $85 \%$ of all cases of impoverishment. ${ }^{1}$ Direct payments are known to affect the poor more than the rich ${ }^{15}$ and a pro-poor tax financed healthcare may protect the most vulnerable against the risk of financial catastrophe in times of illness. Other motivations for pro-poor public healthcare include redressing inequity in the distribution of healthcare, reducing health inequality and raising the human capital of the poor, and thereby the growth potential of the economy. ${ }^{10}$
Several analytical tools are available for assessing pro-poorness of public health financing to inform policymakers about the fairness of existing mechanisms. Arguably the two most influential methods for assessing equity in health financing in recent years are benefit incidence analysis (BIA) and financing incidence analysis (FIA), sometimes referred to as progressivity analysis. ${ }^{16} 17$

BIA estimates the distributional impact of public spending on healthcare. It measures the extent to which different socioeconomic groups benefit from a public subsidy for health through their use of health services. ${ }^{17}$ Conducting BIA involves several key steps including ranking the study population by a living standard measure, assessing the rate of utilisation of different types of health services, estimating the unit cost of each type of service and multiplying the utilisation rates by the unit costs to determine the amount of subsidy. These steps are outlined in table 1 .

\section{Table 1 Key steps in conducting BIA}

\begin{tabular}{ll}
\hline Step & Activity \\
\hline 1 & Select a measure of living standard or SES to rank the population from poorest to richest \\
2 & Estimate the utilisation of different types of health services by different socioeconomic groups \\
3 & Calculate the unit cost (or unit price in the case of private for-profit providers) of each type of health service \\
4 & Multiply utilisation rates by unit costs for each type of health service for each group \\
5 & $\begin{array}{l}\text { If only the distribution of public subsidy is being considered, deduct direct user fee or out-of-pocket payments for each } \\
\text { type of health service for each group }\end{array}$ \\
6 & $\begin{array}{l}\text { Aggregate benefits of utilisation (or public subsidy), expressed in monetary terms, across different types of health } \\
\text { service for each group }\end{array}$ \\
& Evaluate the distribution of benefits or subsidy against some target or ideal distribution, such as distribution according \\
to need
\end{tabular}


BIA results are typically presented either as a percentage share of total benefits accruing to each socioeconomic group or by using concentration curves and concentration indexes (CI). Results presented as a percentage share of benefits are visually appealing and easy to understand but they do not offer a conclusive answer as to whether a distribution is pro-poor or pro-rich. ${ }^{18}$ However, the CI, which is directly related to the concentration curve, quantifies the degree of inequality in the distribution and is the most appropriate when comparing results across many time periods, countries or regions. ${ }^{19}$ Traditionally, the applicability of BIA has been largely confined to the distribution of public subsidy, ${ }^{17}$ but in recent years this has been extended to the private sector. $^{7}$

FIA assesses the distribution of the burden of health financing and sometimes the extent to which this burden affects the underlying distribution of income. ${ }^{20}$ To maintain an equitable health financing system, it is generally believed that payment for healthcare should be on the basis of ATP. FIA therefore measures the progressivity of health financing systems by assessing the departure from proportionality in the relationship between payments for healthcare and ATP. ${ }^{21}$ Table 2 highlights the key steps in conducting FIA. A financing system is progressive when households with higher income contribute a higher share of their income towards health than those with lower income; it is regressive when households with lower income contribute a higher share of their income towards health than those with higher income; and proportional when everyone contributes the same percentage of income regardless of their income level. ${ }^{8} 9$

Assessing the progressivity of a healthcare financing system usually requires examination of the progressivity of each type of financing source before assessing the overall progressivity of the system by weighting the progressivity of the different financing sources by their shares in total health finance. ${ }^{7}$ The degree of progressivity is often expressed in terms of the Kakwani index. ${ }^{22}$
A progressive healthcare financing system typically has a positive Kakwani index while regressive and proportional systems have negative and zero indices, respectively. ${ }^{8}$ A key limitation of progressivity analysis, as indeed of BIA and other such quantitative measures of healthcare financing equity, is that they offer little explanation as to why a distribution is progressive or regressive. In recent years, several qualitative studies have explored the factors influencing the distribution of healthcare financing burden and benefits to help identify the reasons behind the shape of the distribution. ${ }^{8} 23$

\section{THIS STUDY}

Fiji and Timor-Leste, like many LMICs, are committed to the principle of UHC. ${ }^{24}{ }^{25}$ In Fiji, the Ministry of Health (MoH) affirms the right of every citizen, irrespective of geographical location, cultural background or economic status, to equal access to a national health system that provides health services for all in need of care. $^{24} 26$ In Timor-Leste the National Health Sector Strategic Plan 2011-2030 (p.19) clearly stipulates that the "government shall ensure equal access to quality healthcare according to the needs of individuals with the same health conditions." 25 One of the specific health goals of the government is to maintain comprehensive primary and secondary care services that are of good quality and accessible to all Timorese in the next 20 years (until 2030).

To achieve the goal of providing quality healthcare to all citizens, the governments of Fiji and Timor-Leste are seeking ways of reforming healthcare financing. Health services in the public sector in both countries already remain largely free. In Fiji, the government has endorsed a proposal to increase total government health expenditure to at least $5 \%$ of Gross Domestic Product (GDP) with the express aim of expanding access to quality services. ${ }^{26}$ It has also floated the idea of implementing a social health insurance scheme, although a government feasibility study in 2005 suggested it would

\section{Table 2 Key steps in conducting FIA}

\begin{tabular}{ll}
\hline Step & Activity \\
\hline 1 & $\begin{array}{l}\text { Obtain household data set containing data on various mechanisms of health financing in the country (such as taxation, } \\
\text { social and private insurance contributions, and out-of-pocket payments). Indirect taxes have to be estimated from } \\
\text { consumption expenditures based on prevailing tax rates }\end{array}$ \\
The household data set should also contain data on income or consumption expenditure to rank household by \\
socioeconomic status \\
Obtain information on the health financing mix from the NHA or from relevant national institutions, such as the Ministry \\
of Finance, if there is no NHA \\
Weight the household data set to obtain a national perspective. Adjust the household consumption to 'individual level' \\
using a per adult equivalence scale
\end{tabular}

Source: Authors.

FIA, financing incidence analysis; NHA, National Health Accounts. 
be difficult to attract significant enrolment with such a scheme. ${ }^{27}$ In Timor-Leste, reforming the provision of healthcare and its financing is high on the agenda. There have been efforts by the $\mathrm{MoH}$ since 2007 to roll out a Basic Services Package (BSP) and Hospital Services Package (HSP) with the explicit aim of achieving universal coverage. ${ }^{28} \mathrm{~A}$ costing study of primary and hospital care services to assess the level of resources required to finance the health sector has been carried out. ${ }^{29}$ The $\mathrm{MoH}$ is also searching for appropriate health financing mechanisms that tie in with the national decentralisation policy recently instituted to move government and services closer to the population. ${ }^{25}$

The governments of Fiji and Timor-Leste recognise that any modifications to their health financing systems in the pursuit of UHC require good evidence on the equity of present arrangements. The overall aim of this study is to help build this evidence base by undertaking an analysis of equity in health system financing and service use in Fiji and Timor-Leste. The specific objectives differ slightly between the two countries: in Fiji the study will undertake a 'whole-of-system' analysis-integrating public and private sectors-of the equity of health system financing and services use, including who pays for healthcare and who benefits from healthcare spending. In Timor-Leste, the study uses existing quantitative evidence from a recent World Bank health equity and financial protection study ${ }^{30}$ to explore the factors that influence the pro-rich distribution of healthcare benefits.

\section{METHODS}

\section{Setting}

Fiji is a Pacific island nation with a population of about 875000 in 2012. ${ }^{31}$ Approximately $57 \%$ of the population are ethnic Fijians and about $37 \%$ are Indo-Fijian. ${ }^{24}$ The health system of Fiji is the most complex and developed among the Pacific island countries. The government provides the largest share of healthcare services-about $71 \%$ of total health services in $2011 .^{32}$ The private sector is small but has experienced significant growth in recent decades and there are a number of non-government organisations providing specific health services to the public. ${ }^{33}$ Access in terms of availability of basic healthcare is relatively good with primary healthcare services available to about $80 \%$ of the population. ${ }^{34}$ National health indicators, including life expectancy at birth (69 years) and infant mortality rate (18/1000 live-births) are also good compared to developing countries elsewhere. ${ }^{24}$ About $30 \%$ of healthcare expenditure, including $20 \%$ OOP payment, is financed from private sources and $9 \%$ is financed by development partners. ${ }^{35}$ Government health expenditure is almost exclusively financed through taxation. Only $1 \%$ of revenue is raised internally by health facilities through user fees. ${ }^{33}$

Timor-Leste, a new island nation with 1.1 million people, has seen some significant health improvements in its relatively short history. ${ }^{28}$ The 2010 infant mortality rate of 44/1000 live-births and under-five mortality rate of 64/ 1000 were better than the country's Millennium Development Goals (MDG) targets of 53 and 96/1000 live-births, respectively. ${ }^{36}$ In contrast, the maternal mortality ratio of $557 / 100000$ live-births ${ }^{36}$ is among the highest in the Asia Pacific region and more than double the country's MDG target of 252/100 000. A quarter of households travel for more than 2 hours to reach the closest health facility and 1 in 10 households do not consult a health provider when sick. ${ }^{37}$ Total government health expenditure has more than doubled from US $\$ 18.3$ million in 20062007 to US $\$ 38.2$ million in 2011, with much of the increase attributable to the high capital expenditure in rebuilding health infrastructure destroyed during the independence struggle. ${ }^{25}$ Despite this, government health expenditure as a proportion of total government expenditure declined from $7 \%$ in 2007 to $2.9 \%$ in $2011 .^{38}$

\section{Benefit and financing incidence analyses in Fiji Design and data}

The Fiji component of the study will use benefit and financing incidence analyses to assess equity in health financing and service use. The Fiji National Health Accounts (NHA) 2011-2012 and Household Income and Expenditure Surveys (HIES) 2008-2009 will be used to estimate the healthcare financing mix and household contributions to health financing through direct and indirect taxation and OOP payments required for the FIA. Tax thresholds and actual revenue generated through different forms of taxation will be obtained from the Ministry of Finance and will be used to triangulate with estimated tax revenue from the NHA and HIES. The BIA also requires data on health service utilisation and the cost of accessing healthcare. As Fiji has no nationally representative household data for utilisation of healthcare, a cross-sectional household survey will be conducted to obtain estimates of health service use and the cost incurred for using health services. Socioeconomic information will also be collected to enable the ranking of households by their living standards and for the assessment of ATP for healthcare.

\section{Sampling}

A two-stage sampling strategy will be used to select 2000 households, with 1000 each from urban and rural areas. This will enable the determination of prevalence for characteristics with a $95 \%$ CI and a precision of $\pm 3 \%$. It will also allow at least $80 \%$ power and a significance level of $5 \%$ to be able to detect differences of $7 \%$ for comparisons between urban and rural areas. The sample will be selected from 50 enumeration areas (EAs) based on the Fiji Bureau of Statistics (FBoS) census divisions. The EAs will be selected from three of the four main administrative divisions in Fiji. The fourth division will be excluded due to accessibility challenges, the small and dispersed population and study resource constraints. In the first stage, the total sample frame will be divided into six strata and representative samples of urban and rural EAs 
will be selected from these strata to obtain the primary sampling unit (PSU). The sample of rural and urban EAs within each PSU (stratum EA) will be based on probability proportional to size, measured in terms of the total number of households in the frame. In the second stage, we will select 40 households from each of the 50 EAs using systematic random sampling. The sampling interval will be estimated based on the total number of households divided by the sample size. The first house to be visited will be randomly determined.

\section{Data collection}

Electronic data collection involving the use of laptops by enumerators will be employed. The e-questionnaire will be designed using the NOVA Research Company's Questionnaire Development System (QDS) 3.0 and administered with the computer-assisted personal interview (CAPI) program. The questionnaire will be piloted in selected EAs to test logistics and gather information to improve the quality and efficiency of the main survey. Enumerators and supervisors will be trained in e-data collection and administrative procedures including the content of the questionnaire, how to save completed interviews and how to transfer data to the Central Data Processing Centre for the study. A project manual has already been developed and published on the project website: https://research.unsw.edu.au/projects/sustainablehealth-financing-fiji-and-timor-leste-shift-study. The primary caregiver or head of the household will be interviewed in each household. The entire study will be implemented over a period of 3 years from July 2013 to June 2016. Data collection is ongoing.

\section{Factors influencing the distribution of healthcare benefits in Timor-Leste \\ Design and data}

The Timor-Leste component of the study investigates one of the key drivers of the pro-rich distribution of healthcare benefits identified in the recent World Bank health equity and financial protection study-the limited use of hospital services by the poor. ${ }^{30}$ The main question asked will be: why do the poor use less hospital services than the rich in Timor-Leste?

To address this question we will use a mixed methods approach $^{23}$ that combines qualitative and quantitative methods to explore three key dimensions of access: availability (physical access), affordability (financial access) and acceptability (cultural access). The qualitative approach will involve focus group discussions (FGDs) with household members to explore views and experiences about access to hospital care, including the costs of accessing hospital services, the quality of services, and access to and use of hospital referrals. In-depth interviews (IDIs) with healthcare providers will explore the functioning of the referral system and the use of hospital referral by households. Key informant interviews (KIIs) with policymakers will probe into general access to hospital care in Timor-Leste and the functioning of the referral system.
The quantitative aspect will involve a cross-sectional survey of households to identify the factors influencing access and utilisation of hospital services across different socioeconomic groups. Secondary data on distribution of health facilities from the $\mathrm{MoH}$ and hospital referral records of selected Community Health Centres will also be analysed to complement and corroborate data from the household survey. The qualitative and quantitative data will be collected simultaneously and integrated at the data analysis stage in a concurrent triangulation strategy to collaborate and confirm results. ${ }^{23} 39$ The specific research questions, methods to address each including data sources and data collection tools are presented in table 3.

\section{Sampling}

We will follow a similar sampling method as the one proposed for Fiji. A two-stage sampling procedure will be used to select 1500 participants; 750 each from urban and rural areas. The households will be selected from 150 EAs. Administratively, Timor-Leste is divided into 13 districts and 1828 EAs based on the 2010 national census. ${ }^{40}$ The sample frame of 13 districts will be grouped into five strata in the first stage. Representative samples of urban and rural EAs will be selected from these strata to obtain the PSU. The sample of rural and urban EAs within each stratum will be based on probability proportional to size, measured in terms of the total households in the frame. In the second stage, we will select 10 households from each of the 150 EAs using systematic random sampling.

The qualitative component will use a purposive sampling technique to select participants. A total of 20 FGDs, IDIs and KIIs will be conducted. At the household level eight FGDs (two in each stratum), each consisting of approximately 6-8 adult women and men randomly selected, who have not already responded to a household survey, will be carried out. For healthcare providers, we will conduct eight IDIs, two in each stratum, while for policymakers four KIIs will be conducted.

\section{Data collection}

We will begin by conducting four FGDs-two in an urban area and the others in a rural area-to inform the design of the household survey. The household survey will be undertaken using electronic data collection. The e-questionnaire will be translated into one of the national languages-Tetum-which is spoken in all districts, and will be piloted in selected EAs around Dili (the capital) to ensure that all the questions and administrative arrangements work as expected. The questionnaire will be reviewed for cultural appropriateness by a local member of the study team before being rolled out. In addition to socioeconomic information, the equestionnaire will cover the three key dimensions of access: physical accessibility-including distance from health facilities, means of transport, and availability of drugs and medical supplies; financial accessibility-particularly information on costs of accessing health services 


\begin{tabular}{|c|c|c|c|c|}
\hline Research questions & Methods & $\begin{array}{l}\text { Data } \\
\text { sources }\end{array}$ & Data collection tools & $\begin{array}{l}\text { Key } \\
\text { dimensions } \\
\text { of access }\end{array}$ \\
\hline $\begin{array}{l}\text { 1. How does the use of hospital } \\
\text { services (public and private) differ } \\
\text { across socioeconomic groups? }\end{array}$ & Quantitative & $\begin{array}{l}\text { Survey } \\
\text { Documents }\end{array}$ & $\begin{array}{l}\text { Household survey and document } \\
\text { analysis }\end{array}$ & Availability \\
\hline $\begin{array}{l}\text { 2. To what extent does distance from } \\
\text { hospital facilities affect the use of } \\
\text { services? }\end{array}$ & $\begin{array}{l}\text { Quantitative } \\
\text { and qualitative }\end{array}$ & $\begin{array}{l}\text { Survey } \\
\text { Focus } \\
\text { groups } \\
\text { Documents }\end{array}$ & $\begin{array}{l}\text { Household survey, FGD with } \\
\text { household members and } \\
\text { document analysis }\end{array}$ & \\
\hline $\begin{array}{l}\text { 3. What costs do households incur } \\
\text { when accessing hospital services } \\
\text { including costs of transport, medicines, } \\
\text { laboratory tests, consultations, time } \\
\text { away from paid and unpaid work, etc? }\end{array}$ & $\begin{array}{l}\text { Quantitative } \\
\text { and qualitative }\end{array}$ & $\begin{array}{l}\text { Survey } \\
\text { Focus } \\
\text { groups }\end{array}$ & $\begin{array}{l}\text { Household survey and FGD with } \\
\text { households }\end{array}$ & Affordability \\
\hline $\begin{array}{l}\text { 4. To what extent do the costs of } \\
\text { accessing hospital services (if any) } \\
\text { influence utilisation behaviour? }\end{array}$ & $\begin{array}{l}\text { Quantitative } \\
\text { and qualitative }\end{array}$ & $\begin{array}{l}\text { Survey } \\
\text { Focus } \\
\text { groups }\end{array}$ & $\begin{array}{l}\text { Household survey and FGD with } \\
\text { households }\end{array}$ & \\
\hline $\begin{array}{l}\text { 5. What do households think about the } \\
\text { quality of hospital care (public and } \\
\text { private)? }\end{array}$ & $\begin{array}{l}\text { Quantitative } \\
\text { and qualitative }\end{array}$ & $\begin{array}{l}\text { Survey } \\
\text { Focus } \\
\text { groups }\end{array}$ & $\begin{array}{l}\text { Household survey and FGD with } \\
\text { households }\end{array}$ & Acceptability \\
\hline $\begin{array}{l}\text { 6. How does the hospital referral } \\
\text { system work (including referral for } \\
\text { hospital treatment overseas), who gets } \\
\text { access to referrals and who uses this } \\
\text { system? }\end{array}$ & $\begin{array}{l}\text { Quantitative } \\
\text { and qualitative }\end{array}$ & $\begin{array}{l}\text { Survey } \\
\text { Interviews } \\
\text { Documents }\end{array}$ & $\begin{array}{l}\text { Household survey, KIls with } \\
\text { policymakers, IDIs with providers, } \\
\text { FGD with households and } \\
\text { document analysis }\end{array}$ & \\
\hline
\end{tabular}

including transport costs and OOP payments; and cultural accessibility-including information on the quality of health services, referral procedures, attitudes of health workers and the use of traditional medicine. Enumerators and supervisors will be recruited and trained in e-data collection and administrative procedures including training on the content of the questionnaire, how to save completed interviews and how to securely transfer data to the Central Data Processing Centre for the study. In each selected household, the primary caregiver or head of the household will be interviewed.

The qualitative data (apart from the initial 4 FGDs to inform the design of the household survey) will be collected at the same time as the household survey and will be guided by an interview schedule. It will explore several of the key issues covered in the household survey in more depth. This will include topics in the domain of financial, physical and cultural access to health services, particularly access to secondary and tertiary services; healthcare-related payments; and access to domestic and overseas referrals. Interviews will be conducted by two experienced local researchers in Tetum and will be audiotaped for transcription and analysis. The survey will be piloted to test logistics and gather information to improve the main survey.

\section{Data analysis}

The study will be integrated at the data analysis stage, with data from Fiji and Timor-Leste being analysed simultaneously (figure 2 ).
Analysis of the BIA and FIA data from Fiji and the data from the household survey in Timor-Leste will be undertaken using STATA version 13. The BIA data analysis will seek to ascertain whether the distribution of benefits from healthcare spending for a given provider is pro-rich or pro-poor and in line with need for services. We will construct bar charts indicating the relative share of total benefits received by each quintile of a socioeconomic group. We will then compare the distribution of benefits, depicted by the concentration curve, against the $45^{\circ}$ line of perfect equality. Dominance tests will be carried out to ascertain whether the differences are significant. ${ }^{41}$ The gender dimension of benefit from health spending will be given specific attention given the role of women as primary caregivers in times of illness or disability. ${ }^{42}$

The FIA data analysis will assess healthcare financing equity by examining the level of contribution to healthcare (through direct payments and taxation) reported by socioeconomic quintile. We will assess the progressivity of the health financing system by evaluating the payments made towards healthcare across different socioeconomic groups in relation to their ATP. The socioeconomic measure will be based on a household's reported expenditure on food consumption, housing and other non-food items. ${ }^{43}$ We will adjust the total consumption variable to obtain per adult equivalent household consumption using the formula:

$$
\mathrm{AE}_{\mathrm{i}}=\left(\mathrm{A}_{\mathrm{i}}+\alpha \mathrm{K}\right)^{\theta}
$$


Figure 2 Integration of the Fiji and Timor-Leste components of the study. BIA, benefit incidence analysis; FIA, financing incidence analysis; NHA, National Health Accounts; HIES, Household Income and Expenditure Surveys.

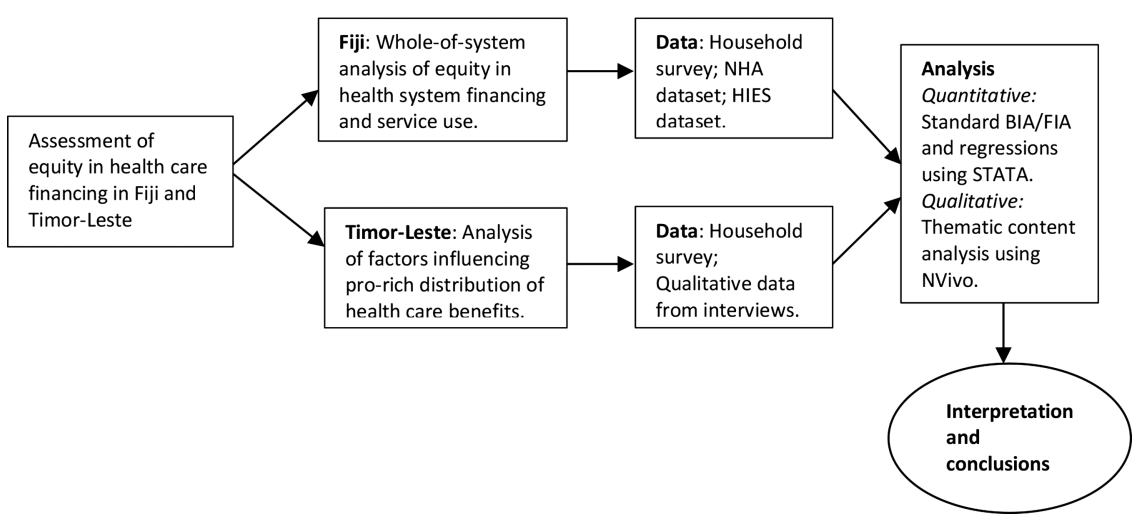

unit cost assumption, which treats the sum of individual fees and government subsidies as constant; the constant unit subsidy assumption, which allocates the same subsidy to each unit of service used irrespective of the fees paid; and the proportional unit cost assumption, which makes the cost of care proportional to the fees paid. ${ }^{46}$

Under FIA, household per capita consumption is often used as a proxy measure for socioeconomic status, especially in LMICs. We will use data on household income from the Fiji Household Income and Expenditure Survey as an alternative measure of socioeconomic status in the sensitivity analysis. Further, there is no consensus on equivalence scales used in FIA to disaggregate household consumption to the individual level. Different scales may result in different progressivity measures. We will test whether any observed differences resulting from the use of different scales are statistically significant using the bootstrap method. ${ }^{47}$ We will adapt the SQUIRE (Standards for QUality Improvement Reporting Excellence) guidelines for reporting the findings for this study. ${ }^{48}$ SQUIRE is generally viewed as appropriate for reporting mixed-methods studies such as this one.

\section{Data management and quality assurance}

All research materials and data from this study will be held and preserved in accordance with the UNSW Research Data management guidelines: http://www.gs. unsw.edu.au/policy/documents/researchdataproc.pdf. Quality assurance procedures will be built into the data management system and implemented alongside other data management activities to ensure timely detection and resolution of errors in the data. A central project database that is password protected will be established using the UNSW research data portal. This will be the ultimate home of the data and will be established in advance of data collection. Access to the database will be given only to members of the study team and country institutions collaborating on the project such as the MoH. The use of e-data collection method means that data can be transferred directly from the field to the project central database immediately after collection. There will be a dedicated staff member to receive all data and prepare it for analysis. The data will be archived using the UNSW long-term data archiving system. 


\section{DISCUSSION}

This study seeks to support country efforts towards achieving UHC by providing policymakers in Fiji and Timor-Leste with evidence on the equity of their current health financing arrangements. In Fiji, this involves the application of internationally accepted methods for measuring health financing equity, namely BIA and FIA. ${ }^{49}$ In Timor-Leste, it makes advances on these standard methods to explore the reasons for the inequitable distribution of healthcare benefits using qualitative and quantitative approaches. Regionally, the timing of the study is ideal. There is growing interest in 'pro poor' reforms across the Asia-Pacific region particularly in view of the targets established by the MDGs. The comprehensiveness of this study in terms of covering both the public and private sectors will also mean our findings are relevant to a growing number of countries in the region with a thriving private sector.

For Fiji and Timor-Leste the potential benefits from this study are significant. In Fiji, the study represents the first attempt to undertake a nationally representative household survey on utilisation of healthcare services. It is also the first attempt to use an electronic data collection system in a household survey in Fiji. The recommendations made will assist the FBoS to improve national surveys by capturing essential parameters of healthcare utilisation, health expenditure by households and socioeconomic stratifiers necessary for estimating household wealth indexes. The introduction of e-data collection may also help mobilise support within FBoS for a move from paper-based to electronic data collection, improving further the overall efficiency of data gathering and analysis in the country.

In Timor-Leste the National Directorate of Statistics has already moved to e-data collection for national household surveys; this study will further strengthen the development of that system (e-data collection) in the country by providing additional training to local enumerators working through the Directorate. In Timor-Leste and Fiji the study will build local capacity for health financing equity analysis within the $\mathrm{MoH}$ and collaborating universities by providing practical training in BIA and FIA. A user-friendly toolkit on how to analyse health financing equity will be developed for use by policymakers and development partners in the region.

The results will be disseminated through stakeholder meetings, targeted multidisciplinary workshops, seminars, journal publications, policy briefs, podcasts and the use of other electronic and web-based technologies appropriate to the audiences to maximise awareness and utilisation of the findings.

\footnotetext{
Author affiliations

${ }^{1}$ School of Public Health and Community Medicine, University of New South Wales, Sydney, Australia

${ }^{2}$ Centre for Health Information, Policy and Systems Research, Fiji National University, Suva, Fiji

${ }^{3}$ Faculty of Medicine and Health Sciences, National University of Timor-Leste (UNTL), Dili, Timor-Leste
}

${ }^{4}$ Faculty of Public Health \& Policy, London School of Hygiene and Tropical Medicine, London, UK

${ }^{5}$ Health Economics Unit, School of Public Health and Family Medicine, University of Cape Town, Cape Town, South Africa

${ }^{6}$ Faculty of Pharmaceutical Sciences, Department of Social and Administrative Pharmacy, Khon Kaen University, Khon Kaen, Thailand

${ }^{7}$ London School of Hygiene and Tropical Medicine, London, UK

${ }^{8}$ The George Institute, Sydney, Australia

${ }^{9}$ Department of Global Health and Development, London School of Hygiene and Tropical Medicine, London, UK

Contributors ADA contributed to the design of this study and drafted the manuscript. JP contributed to the drafting of the manuscript. AH contributed to the design of the study and reviewed the manuscript. WI and JM provided the local contents for Fiji and Timor-Leste. LG, JEA, AM and SJ contributed to the design of the study and reviewed the manuscript. VW conceived and designed the study, and oversaw the preparation of the manuscript. All authors read and approved the final manuscript.

Funding Funding for this study is provided by the Australian Aid through the Australian Development Research Awards (ADRAs) scheme.

Competing interests None.

Ethics approval The study is approved by the Human Research Ethics Committee of University of New South Wales, Australia (Approval number: HC13269); the Fiji National Health Research Committee (Approval \# 201371); and the Timor-Leste Ministry of Health (Ref MS/UNSW/VI/218).

Provenance and peer review Not commissioned; peer reviewed for ethical and funding approval prior to submission.

Data sharing statement No additional data are available.

Open Access This is an Open Access article distributed in accordance with the Creative Commons Attribution Non Commercial (CC BY-NC 4.0) license, which permits others to distribute, remix, adapt, build upon this work noncommercially, and license their derivative works on different terms, provided the original work is properly cited and the use is non-commercial. See: http:// creativecommons.org/licenses/by-nc/4.0/

\section{REFERENCES}

1. Krishna A. Pathways out of and into poverty in 36 villages of Andhra Pradesh, India. World Dev 2006;34:271-88.

2. Jacobs $\mathrm{B}$, Ir $\mathrm{P}$, Bigdeli $\mathrm{M}$, et al. Addressing access barriers to health services: an analytical framework for selecting appropriate interventions in low-income Asian countries. Health Policy Plan 2012:27:288-300.

3. WHO. World Health Report 2000: health systems: improving performance. Geneva: World Health Organization, 2000.

4. WHO. The World Health Report 2010-financing for universal coverage. Geneva: World Health Organization, 2010.

5. WHO. The World Health Report 2013—research for universal health coverage. Geneva: World Health Organization, 2013.

6. Limwattananon S, Vongmongkol V, Prakongsai $\mathrm{P}$, et al. The equity impact of Universal Coverage: health care finance, catastrophic health expenditure, utilization and government subsidies in Thailand. Thailand: Consortium for Research on Equitable Health Systems (CREHS), 2011.

7. Mills A, Ataguba JE, Akazili J, et al. Equity in financing and use of health care in Ghana, South Africa, and Tanzania: implications for paths to universal coverage. Lancet 2012;380:126-33.

8. Mejia A. Is tax funding of health care more likely to be regressive than systems based on social insurance in low- and middle-income countries? Lecturas de Economía 2013;78:229-39.

9. Schieber G, Baeza C, Kress D, Financing Health Systems in the 21st Century. In: Jamison DT, Breman JG, Measham AR, Alleyne G, Claeson M, Evans DB, et al. eds. Disease Control Priorities in Developing Countries. New York: The World Bank and Oxford University Press, 2006.

10. O'Donnell O, van Doorslaer E, Rannan-Eliya RP, et al. The Incidence of Public Spending on Healthcare: Comparative Evidence from Asia. World Bank Econ Rev 2007;21:93-123.

11. Meessen B, Bigdeli M, Chheng K, et al. Composition of pluralistic health systems: how much can we learn from household surveys? An exploration in Cambodia. Health Policy Plan 2011;26(Suppl 1):i30-44. 
12. Xu K, Evans DB, Carrin G, et al. Protecting households from catastrophic health spending. Health Aff 2007;26:972-83.

13. Mills A. Health Care Systems in Low- and Middle-Income Countries. N Engl J Med 2014;370:552-7.

14. OECD/World Health Organization. Health at a Glance: Asia/Pacific 2010. OECD Publishing, 2012.

15. Ataguba JE-O. Reassessing catastrophic health-care payments with a Nigerian case study. Health Econ Policy Law 2012;7:309-26.

16. O'Donnell O, van Doorslaer E, Rannan-Eliya RP, et al. Who pays for health care in Asia? J Health Econ 2008;27:460-75.

17. Wagstaff A. Benefit-incidence analysis: are government health expenditures more pro-rich than we think? Health Econ 2012;21:351-66.

18. Mclntyre D, Ataguba JE. How to do (or not to do) ... a benefit incidence analysis. Health Policy and Planning 2011;26:174-82.

19. Wagstaff A, Bilger M, Sajaia Z, et al. Health equity and financial protection. Washington DC: World Bank, 2011.

20. Wagstaff A. Reflections on and alternatives to WHO's fairness of financial contribution index. Health Econ 2002;11:103-15.

21. Yu CP, Whynes DK, Sach TH. Assessing progressivity of out-of-pocket payment: with illustration to Malaysia. Int $J$ Health Plann Manage 2006;21:193-210.

22. Kakwani NC. Measurement of tax progressivity: an international comparison. Econ J 1977;87:71-80.

23. Macha J, Harris B, Garshong B, et al. Factors influencing the burden of health care financing and the distribution of health care benefits in Ghana, Tanzania and South Africa. Health Policy Plan 2012;27 (Suppl 1):i46-54.

24. WHO. The Fiji Islands Health System Review. Health Syst Transition 2011;1(1):1-139.

25. MoH. National health sector strategic plan 2011-2030. Dili, Timor-Leste: Ministry of Health, 2011.

26. Government of Fiji. Fiji National Health Account (NHA) report 2007/ 2008. Suva: Ministry of Health, 2009.

27. Rannan-Eliya R, Irava W, Saleem S. Assessment of Social Health Insurance Feasibility and Desirability in Fiji. Suva: Ministry of Health and World Health Organization; 2013.

28. Asante $A D$, Martins $N$, Otim ME, et al. Retaining doctors in rural Timor-Leste: a critical appraisal of the opportunities and challenges. Bull World Health Organ 2014;92:277-82.

29. Ensor T, Firdaus H, Lievens T. Health facilties costing in Timor Leste: Final Report. Oxford, UK: Oxford Policy Management; 2010.

30. World Bank. Health equity and financial protection report: Timor-Leste (Unpublished). Washington DC: The World Bank, 2014

31. World Bank. World development report 2014: risk and opportunitymanaging risk for development. Washington DC: World Bank, 2013.
32. Irava W, Prasad R. A case study on the public and private mix of health services in Fiji. Suva, Fiji: Centre for Health Information, Policy and Systems Research (CHIPSR), Fiji National University, 2012.

33. Asante A, Roberts G, Hall J. A review of health leadership and management capacity in Fiji. Sydney: University of New south Wales, Human Resources for Health Knowledge Hub, 2011.

34. Jerety J. Primary health care: Fiji's broken dream. Bull World Health Organ 2008;86:166-7.

35. Fiji Ministry of Health. Fiji National Health Account (NHA): National Health Expenditures 2009-2010. Suva, Fiji: Ministry of Health, 2011.

36. MoF. Timor-Leste Demographic and Health Survey 2009-2010. Dili: National Statistics Directorate, Ministry of Finance, 2010.

37. Martins N, Trevena L. Taking healthcare to the people in Timor-Leste. Health in South-East Asia: SEARO Newsletter 2011;4(2):4-6.

38. MoH. Human resources for health country profile of Timor-Leste. Dili Ministry of Health, 2012.

39. Creswell JW. Research design: qualitative, quantitative and mixed methods approaches (2nd edition). London: Sage Publications, 2003.

40. Timor-Leste National Directorate of Statistics. 2010 Population and Housing Census: Population Distribution by Administrative Areas. Dili, Timor-Leste: National Directorate of Statistics, 2011.

41. Limwattananon S, Prakongsai P, Tangcharoensathien V. The equity impact of Universal Coverage: health care finance, catastrophic health expenditure, utilization and government subsidies in Thailand Consortium for Research on Equity in Health Systems (CREHS) Report. 2011.

42. Guberman N, Maheu P, Maillé $C$. Women as family caregivers: why do they care? The Gerontologist 1992;32:607-17.

43. Akazili J, Garshong B, Aikins M, et al. Progressivity of health care financing and incidence of service benefits in Ghana. Health Policy Plan 2012;27(Suppl 1):i13-22.

44. Deaton A, Zaidi S. Guidelines for constructing consumption aggregates for welfare analysis. Washington DC: World Bank, 2002.

45. Patton MQ. Qualitative research and evaluation methods. 3 edn. Sage Publications, 2002.

46. World Bank. Health equity and financial protection report-Vietnam. Washington DC: The World Bank, 2012. Contract No: 71257.

47. Munge $\mathrm{K}$, Briggs $\mathrm{AH}$. The progressivity of health-care financing in Kenya. Health Policy Plan 2014;29:912-20.

48. Ogrinc G, Mooney SE, Estrada C, et al. The SQUIRE (Standards for QUality Improvement Reporting Excellence) guidelines for quality improvement reporting: explanation and elaboration. Quality and Safety in Health Care 2008;17(Suppl 1):i13-i32.

49. O'Donnell O, van Doorslaer E, Rannan-Eliya R, et al. The incidence of public spending on healthcare: comparative evidence from Asia. World Bank Econ Rev 2007;21:93-123. 